\title{
Gas Turbine Engine Implementation of Gamma Titanium Aluminide
}

\author{
C. M. Austin and T. J. Kelly \\ GE Aircraft Engines \\ Cincinnati OH 45215
}

\begin{abstract}
Gamma titanium aluminide will be introduced into commercial service during 1997, replacing superalloys, following a relatively brief application development and engine testing program. This paper will describe gamma and discuss its transition from laboratory curiosity to engineering material.
\end{abstract}

\section{Introduction}

Gamma titanium aluminide, TiAl, is the base for an emerging class of low-cost, low-density alloys with unique properties. Cast processing [1] is being used for production of initial components. The progress of this effort has been reported previously [2, 3]; a general review of gamma has also been published by Kim [4].

It is interesting to note in the context of these proceedings that the implementation of gamma has been led by superalloy metallurgists after initial development by titanium metallurgists. This may be a result of better familiarity with the applications for which gamma is most suited as well as the greater acceptance of cast processing by the superalloy community.

\section{Physical Metallurgy}

"Gamma" alloys are actually mixtures of the neighboring aluminide phases $\mathrm{Ti}_{3} \Lambda \mathrm{l}$ (alpha-two, hexagonal) and TiAl (gamma, tetragonal), Figure 1 . The morphology of these constituents is complex, and depends in complex ways on aluminum level, processing and heat treatment. The so-called duplex structure is generally preferred, Figure 2, which results from heat treatment in the $\alpha+\gamma$ phase field. On cooling, the structure transforms to a mixture of gamma grains and colonies of lamellar gamma and alpha-two. This is superficially similar to typical alpha-beta titanium alloys.

The lamellar constituent actually begins to form during cooling within the $\alpha+\gamma$ phase field. There is little interfacial energy involved in the formation of gamma laths within the alpha phase, and this is the most expedient way in which to maintain the equilibrium proportions of the two phases. Upon cooling below the eutectoid, additional gamma phase forms, either through thickening of existing laths or creation of new laths. The alpha phase orders to become alpha-two; at this point, the alpha-two laths make up a small fraction of the lamellar constituent.

The presence of gamma grains, as opposed to laths, must arise from other processes. Extended periods low within the $\alpha+\gamma$ phase field can lead to coarsening of gamma laths. One form of coarsened gamma can be seen along the edges of lamellar grains in Figure 2. Alternatively, gamma grains can form in the interdendritic, aluminum-rich areas of the microstructure during cooling from the casting operation and persist through subsequent heat treatrnent provided temperatures are kept low and/or aluminum is high.

$$
\text { Superalloys } 1996
$$

Edited by R. D. Kissinger, D. J. Deye, D. L. Anton,

A. D. Cetel, M. V. Nathal, T. M. Pollock, and D. A. Woodford

The Minerals, Metals \& Materials Society, 1996

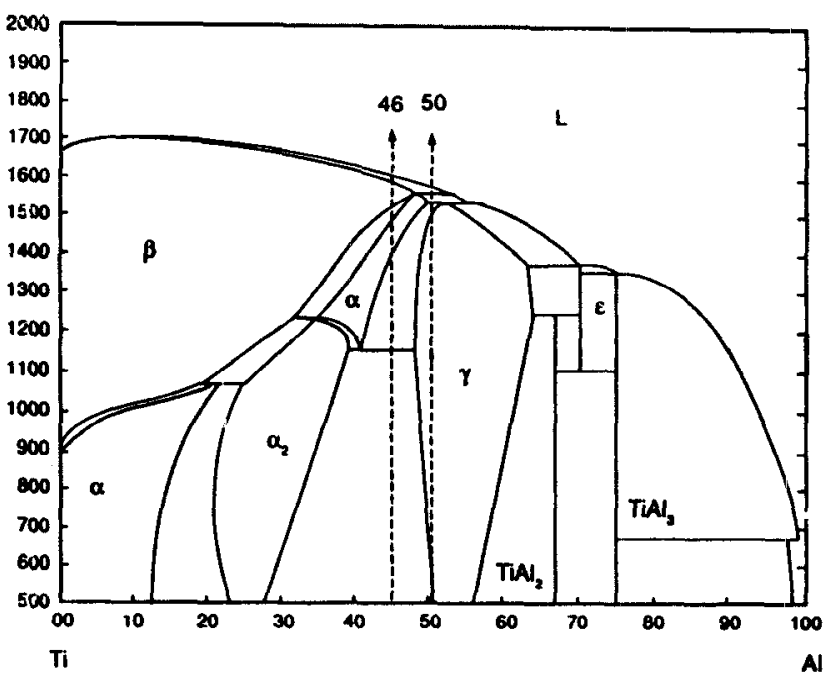

Figure 1: Titanium-aluminum phase diagram, showing two-phase regime of engineering gamma alloys (temperatures in ${ }^{\circ} \mathrm{C}$, composition in atomic percent).

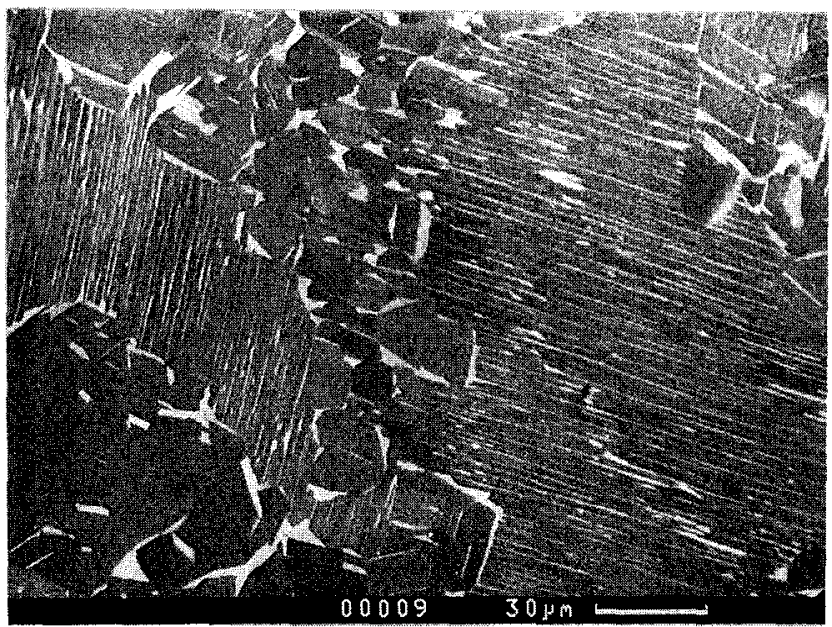

Figure 2: Microstructure of a gamma alloy with the duplex grain structure; the lighter phase is alpha-two. 


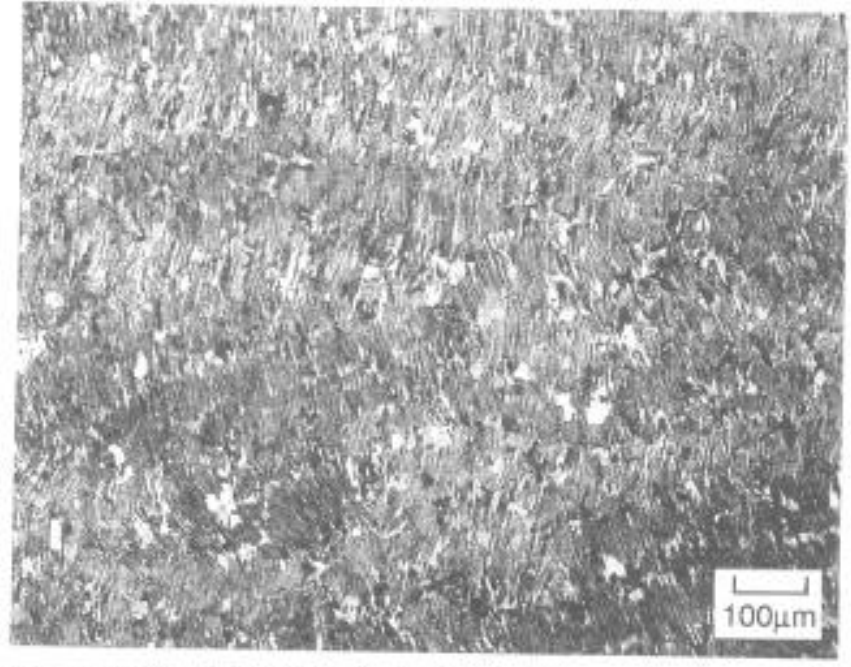

Figure 3: Microstructure of as-cast gamma showing typical columnar, lanellar grains.

The management of gamma grain creation and persistence is particularly important in the thermal processing (HIP and heat treatment) of cast material. As-cast structures consist almost entirely of columnar grains of the lamellar constituent, with a small number of gamra grains in the interdendritic regions, Figure 3 . The first thermal exposure in the $\alpha+\gamma$ field should be at low temperature, in order to at least preserve the gamma grains, if not grow them.

A number of minor microstructural features ane often found. The most prominent is the appearance of plates of alpha-two in gamma grains after a thermal treatment constituting an upquench; this results from the nced for gamma grains to reject titanium to satisfy the lever law. Just as gamma laths will appear in alpha grains on cooling, alpha plates will form in gamma on heating. The difference is that there are four habit planes in the latter case.

The duplex structure provides a useful balanoc of properties, involving several factors in addition to the usual benefit of controlled grain size. Neither fully gamma or fully lamellar structures are as ductile. The lamellar constituent is associated with toughness and fatigue crack growth resistance, a ramification of crack branching and deflection. The ductility of the gamma phase is thought to depend on having minimum aluminum; barring excessive segregation, this is assured by the presence of alpha-two.

\section{Alloys}

The objectives in gamma alloy development include increasing ductility, oxidation resistance, tensile strength, creep resistance and processability. The alloying elements of greatest interest are described below:

Duxcility:
Oxidation resistance:
Tensile strength:
Creep resistance:
Processability:

$$
\begin{aligned}
& \mathrm{Cr}, \mathrm{Mn}, \mathrm{V} \\
& \mathrm{Cr}, \mathrm{Nb}, \mathrm{Ta}, \mathrm{Zr} \\
& \mathrm{Cr}, \mathrm{Ta}, \mathrm{W}, \mathrm{B} \\
& \mathrm{Cr}, \mathrm{W}, \mathrm{Ta}, \mathrm{C}, \mathrm{Si} \\
& \mathrm{Mo}, \mathrm{B} \text { (wrought) }
\end{aligned}
$$

As for superalloy development during the early (and perhaps late) years, the actual effects of various elements is a subject of some debate. An extensive cast alloy development program funded at GE by the U. S. Navy has sought to quantify the effects of many elements on castability and properties, but has only partially succeeded due to the complexity of the system and non-linear effects.
The most significant compositional factor is aluminum level. Properties and structure vary greatly over the range of interest, about 45 to $49 \%$ (atomic), Figure 4. Properties can vary dramatically even over a reasonable specification range. Some properties are clearly related to structural effects of aluminum, notably toughness. Tensile properties do not appear to depend on any single, easily observed structural feature in cast material.

$\mathrm{GE}$ is implementing an alloy that contains chromium and niobium [5]. Both contribute to oxidation resistance and creep strength, while chromium increases ductility. The alloy is known as " $48-2-2$ " but is nominally $\mathrm{Ti}-47 \mathrm{Al}-2 \mathrm{Cr}-2 \mathrm{Nb}$ in atomic percent. The specification range is currently 46.5 to $48.2 \%$, which is narrow with respect to process capability but wide with respect to property variations.

The aforementioned cast alloy development program has identified a $\mathrm{Cr}-\mathrm{Nb}$-Ta alloy with significantly greater creep strength than $48-2-2$ and other current alloys, Figure 5 .

\section{Processing}

For a varicty of reasons, current implementation efforts by $\mathrm{GE}$ and others are pursuing cast processing. First, the limited ductility of gamma alloys requires that deformation processing be done isothermally or in at thick can to prevent surface chilling; this sort of processing is used for only the most critical parts in aircraft engines where the expense can be justified. Second, the sorts of application for which gamma is appropriate are parts that are currently cast, and are generally not amenable to wrought processing. The specific components where wrought processing might be desirable are those that are most critical, which near-term efforts are correctly avoiding until more experience is gaired.

The casting of gamma presents no special challenges to the conventional titanium VAR casting process, but a great deal of knowledge must be accumulated before the production of gamma components becomes as routine as conventional alloys. There are certain processing steps that pose cost and quality issues.

The production and qualification of ingots is more difficult than for titanium or nickel atloys: 1) triplemelt VAR fails to adequately mix aluminum and titanium uniformly, 2) analysis of aluminum to the required accuracy is difficult, 3) preparation of casting VAR electrodes by the usual titanium process (forging of a large VAR ingot) is not possible, and 4) the supplier base in this area is small. Oremet and Howmet are actively developing modified processes for gamma. At some point, revert material must be qualified.

The casting operation itself can make use of standard titanium foundry practices, with modified mold configurations to prevent cracking. Precision Castparts, Howmet, IMI-Tiline and others have all had significant casting experience with gamma. A large variety of shapes and sizes have been produced and at this point no significant limitations are seen. As for any alloy, significant development is required for each new component to find casting parameters that produce a sound part.

Thermal processing (HIP and heat treatment) has been modified recently to reduce cost and the sensitivity of gamma to aluminum variations. The use of standard HIP cycles, such as those used for conventional titanium castings, reduces cost and cycle time. Low temperature heat treatments and correct sequencing can "lock in" gamma grains and maintain more uniform structure and propertics over the aluminum specification range.

Structural castings usually require in-process repair, generally by welding. Common defects include HIP dimples, tears and small unfilled areas. For gamma to be viable, equivalent repair processes are required. Perhaps surprisingly in view of its ductility, gamma castings have been shown to be readily weld repairable using matching filler metal. Fabrication welding (EB, GTA) has also been demonstrated using special post-weld procedures. 

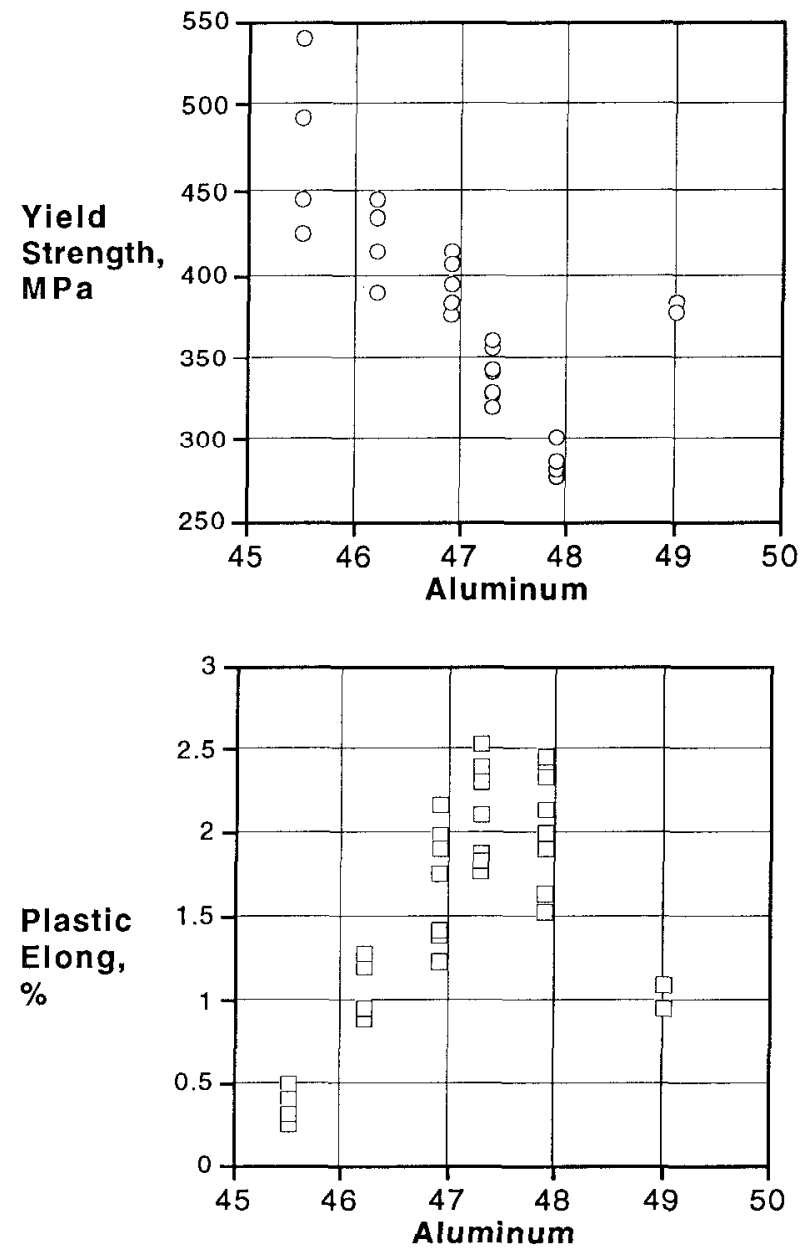

Figure 4: Effect of aluminum level on tensile properties of an alloy with $2 \mathrm{Cr}$ and $2 \mathrm{Nb}$, investment cast, various heat treatments.

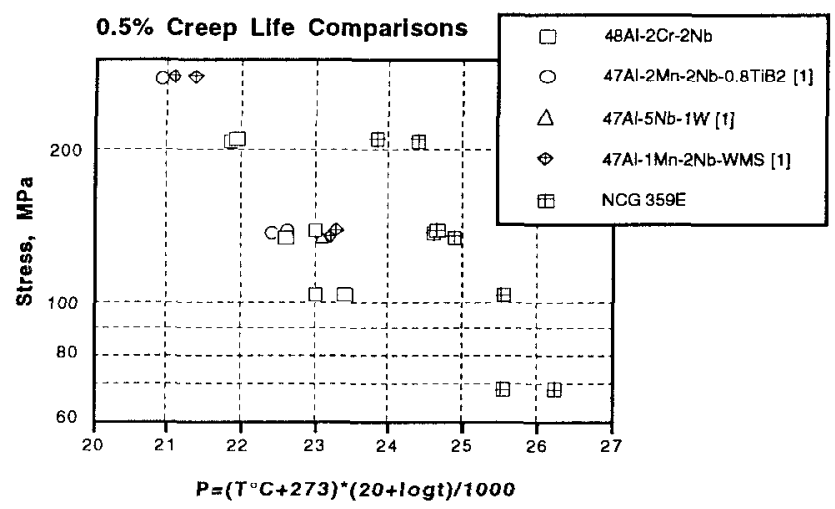

Figure 5: Creep strength of various gamma alloys, including the recently developed cast alloy NCG 359.

\section{Properties}

Density: The density of gamma is half that of nickel alloys and about $10 \%$ lower than titanium alloys

Ductility: Gamma alloys can have a fair degree of ductility, about $2 \%$ at room temperature and 3 to $4 \%$ at typical operating temperatures. The wide aluminum range over which the gamma phase is stable means that titanium and aluminum atoms have some tolerance for being on each other's sites, a helpful attribute for slip, twinning, and the accommodation of the debris of their interactions. The alpha-two phase field is also wide. As discussed above, neither phase is very ductile in isolation, however. The presence of two phases does several things: 1) grain growth is restricted, 2) the aluminum contents of the gamma and alpha-two phases are pinned to the low and high ends of their respective ranges, 3) lamellar grains are formed in which interfaces may promote or accommodate extra deformation modes, and 4) oxygen or other impurities are gettered within one phase or at interfaces.

At this point, it can be concluded from analysis [6] and engine testing [3] that gamma has sufficient ductility to survive normal manufacturing, assembly and engine operations. Concerns remain for special situations, including field service operations and impact damage. The effects of long-term exposures to engine environments are, of course, largely unknown and will remain so for some time.

Strength: Gamma has relatively low yield strength, about 300 to $500 \mathrm{MPa}$ (45 to $70 \mathrm{ksi}$ ). In one sense this is good: gamma might otherwise have less ductility to the extent that fracture is cleavage, i.e., controlled by normal stress. Allowable stress will be limited by defect behavior in most situations, so the low tensile strength may not be a significant limitation.

Fatigue strength is very good relative to yield strength, with ratios of endurance limit to yield strength approaching $100 \%$. The slope of $\mathrm{S}-\mathrm{N}$ curves is relatively flat. This behavior is a simple consequence of the limited ductility of intermetallics; metal fatigue is, after all, a consequence of plasticity.

Creep strength is good up to about $800^{\circ} \mathrm{C}$. The specific creep strength is better than cast Alloy 718 beyond about $600^{\circ} \mathrm{C}$, but never quite matches gamma-prime strengthened alloys.

Modulus: Perhaps the most unique property of gamma is its high modulus, $175 \mathrm{GPa}(25 \mathrm{msi})$. The specific modulus is $50 \%$ higher than any commonly used alloy.

Thermal expansion: The coefficient of expansion, alpha, of gamma is somewhat higher than titanium, and substantially lower than nickel alloys. Depending on the temperature range of interest, gamma is a candidate for specialty low expansion nickel alloys such as the $90 \mathrm{X}$ series.

Defect tolerance: The fracture toughness of gamma alloys range from 15 to $25 \mathrm{MPa} \sqrt{\mathrm{m}}$. For reasonable assumptions for defect sizes in castings, this will restrict allowable stresses to somewhat below yield strength. The fatiguc crack growth curves for gamma have high Paris-region slopes, dictating that a threshold criteria be applied [7]. Gamma alloys exhibit true threshold behavior at about 5 to 8 $\mathrm{MPa} \sqrt{\mathrm{m}}$, which further limits allowable stress range in components subject to vibratory loads. The threshold is low relative to nickel alloys, but is higher than titanium alloys, which do not show true thresholds.

Oxidation and corrosion resistance: On the basis of laboratory testing, alloys with a $\mathrm{Cr}+\mathrm{Nb}+\mathrm{Ta}$ of $4 \%$ or more have excellent oxidation resistance up to about $800^{\circ} \mathrm{C}$ [8]. Oxidation/corrosion burner rig tests have shown equal or better resistance than nickel alloys such as René 80 . Correlation between laboratory tests and service behavior is not established, however. As is common for titanium-base materials, laboratory tests indicate great sensitivity to hot salt stress corrosion cracking, but it remains to be seen if this is of significance in service. 
Coatings have been identified for protection from the environment, but the current view is that a coating will not be required.

Ignition: Various types of tests have shown that gamma is much less likely to ignite than titanium alloys. The ability to contain a titanium fire, as is often required of compressor cascs, is only somewhat better than titanium alloys.

\section{Applications}

There are several application areas that provide substantial payoff given the properties above. Ganma has $50 \%$ higher densityadjusted stiffness than all other commonly used engineering alloys. Applications are envisioned in a wide range of structural parts on this basis, including low temperature applications. COE is lower than nickel alloys, which is also of benefit in structures that determine clearances at seals and airfoil tips.

Useful creep strength extends to above $750^{\circ} \mathrm{C}$, exceeding that of 718 and Rene 220. This temperature regime corresponds to compressor discharge air in advanced engines, to which many components are exposed. While specific creep strength is lower than gamma-prime strengthened cast alloys such as IN 100 or Rene 77, many components are not strength-limited. The best example is a low pressure turbine blade, which has a thickness set by manufacturing and aeromechanical requirements.

The ignition resistance of gamma is a required feature for some of the applications noted above, and may be the key feature of others. Some components are made of steel or nickel only because titanium would present a fire hazard.

Finally, there are some parts for which substitution for gamma may represent a cost reduction, which is an unusual feature for an advanced material. This stems from the low theoretical raw material cost and similar processing requirements.

\section{Evaluation}

GE initiated efforts with several titanium casting suppliers to produce cast gamma components in 1989. Being able to show design customers actual components proved to be a strong factor in gaining acceptance. Still, the risk and expense involved in implementing gamma was clearly high. In 1991, an engine project with a challenging weight goal found that gamma could provide more than half of the needed weight reduction. This led to a program to test gamma low pressure turbine blades in a factory CF6-80C2 engine.

Certain modifications to the blade and disk design were required for this test. I.PT blades ane leaned to counterhalance aerodynamic and centrifugal forces. This reduces bending stresses at the dovetail. The lower density of gamma required greater lean. The different thermal expansivity of gamma and the 718 disk material would prevent even loading across the tangs of a multiple-tang dovetail, so a single tang dovetail was designed. The different modulus to density ratio shifted a bladed disk system vibration mode to nearredline $\mathrm{rpm}$; damper pins were used to avoid that problem (normally, the aeromechanical design would be changed to avoid such modes).

Blades were produced by a non-production process consisting of over-sized castings that were ECM'ed and otherwise machined to shape. Many processes were given their first tests during this program, and a great deal of attention was required from ingotmaking through finish machining and assembly. It was during the last step that the authors became aware of the greatest benefits of ductility, though no blades were damaged.

The engine was first run to full power in June, 1993. Due to the nature of gamma, most observers in attendance believed if the blades survived that event, they would survive the rest of the test. This proved to be the case, though not without a few tense moments. The engine was run through many cycles for various other purposes, then put through 1000 simulated flight " $\mathrm{C}$ " cycles. The post-run condition of the rotor, Figure 6, was excellent, showing no distress related to the use of gamma. Wear occurred at the damper pins and at the shroud interlocks, but this was considered normal.

The rotor was disassembled, the blades were refurbished, and the rotor reassembled. An additional $500 \mathrm{C}$ cycles were imposed during 1994 without incident. Demonstrating the ability to handle blades exposed to service conditions was considered a major milestone.

\section{Transition}

During the period of the CF6-80C2 test, GE adopted a risk-phased approach to gamma implementation. A small non-critical component was selected, the GE90 transition duct beam, Figure 7. Normally made from René 77, this part prevents duct panels from buckling during engine surges. Gamma beams completed rig and engine testing during 1995 and have been certified. Production orders will soon be placed and gamma beams will be installed in GE90's starting in early 1997.

GE has also successfully engine tested several air/oil seal supports in an advanced $\mathrm{F} 404$ derivative engine.

Low pressure turbine blades provide the greatest weight-savings of any gamma application, up to $45 \mathrm{Kg}(100 \mathrm{lb})$ per stage. A NASA Aerospace Industry Technology Progran was awarded during 1995 that will design and produce GE90 Stage 6 blades for certification testing. This is a heavily cost-shared program being conducted by GE, Chromalloy, Howmet, Oremet and PCC; the purpose of this type of program is to encourage early adoption of new technology by addressing the specific barriers to implementation.

For gamma, the specific barriers being addressed by this program are 1) ingot making, particularly with respect to aluminum control and cost, 2) net-shape casting and subsequent processing, 3) design, including the accommodation of casting limitations and the unique properties of gamma, 4) blade tip rubs, in terms of survivability and proper shroud cutting behavior, and 5) resistance to foreign object damage. FOD is a particular concern, since gamma will have substantially lower capability than superalloys. An impact test program has been devised that will utilize special cast-to-shape specimens, Figure 8 , having gage sections closely representing the profiles of candidate leading edge designs.

In addition, numerous metallurgical issues and unknowns remain for gamma. The evolution of the microstructure through solidification and heat treatment is complex, and the structure itself is complex. Compositional and processing variations generally change many aspects of the structure simultaneously, which has confounded attempts to isolate effects on properties.

\section{Significance}

The introduction of new materials occurs at infrequent intervals. Among the many "revolutionary" materials that the U.S. Integrated High Performance Turbine Engine Technology (IHPTET) program has fostered, gamma appears to be the one that will have the greatest impact. This is an outcome of several factors. First, the material has significant, multiple payoff areas. Second, an engineering, component-oriented approach was taken that demonstrated partsmaking capability and focused on specitic design requirements. Third, and most important, gamma components can be produced at a small cost premium over conventional materials.

\section{Acknowledgments}

The success of gamma is the result of cfforts by a large number of people, from those that first explored the titanium aluminide system to those that designed, produced and tested engine components. The support of the U.S. Air Force, Navy and NASA is gratefully acknowledged. 


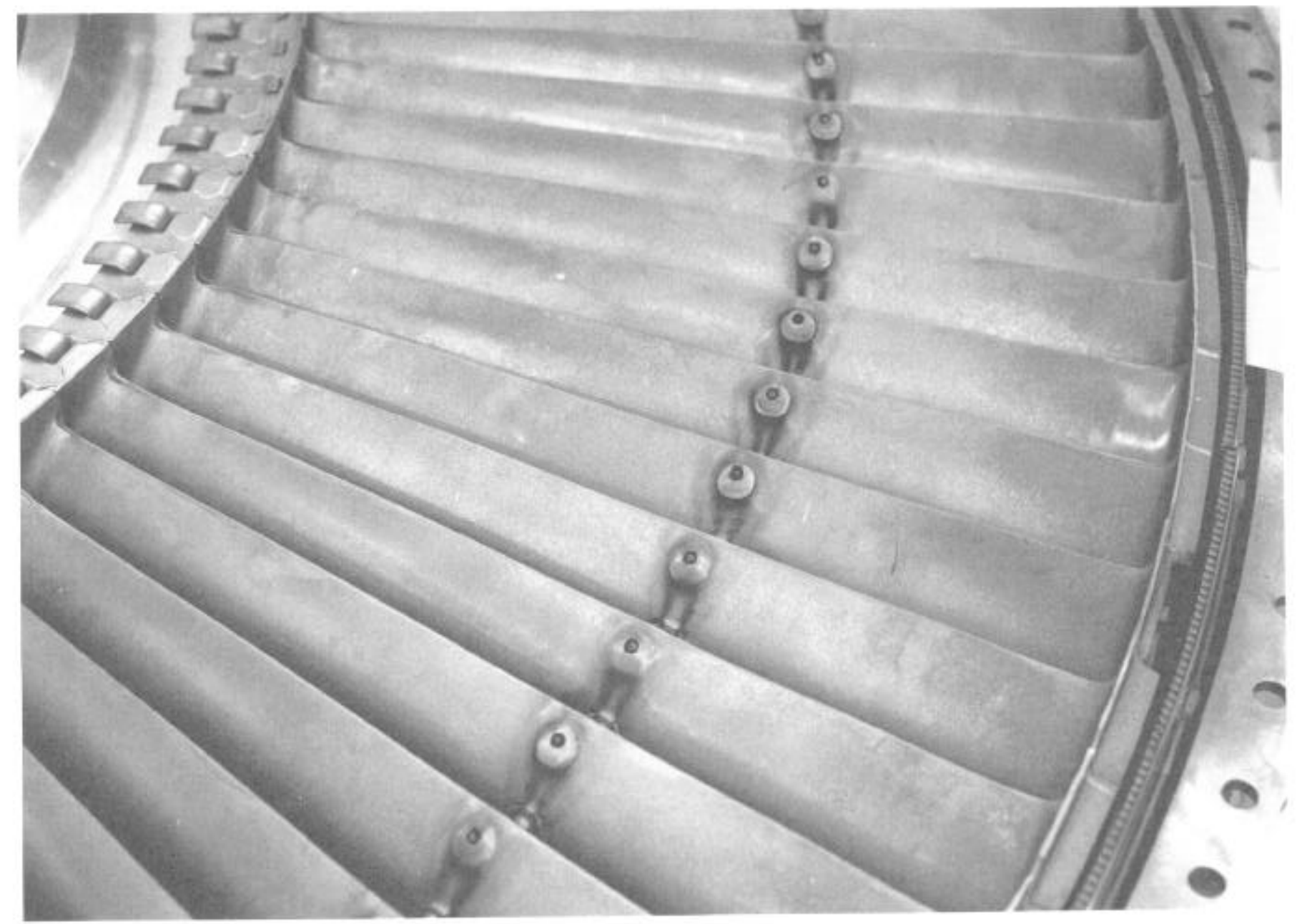

Figure 6: CF6.80C2 stage 5 rotor made up from gamma blades, after 1000 simulated flight cycles in a factory engine test.

\section{References}

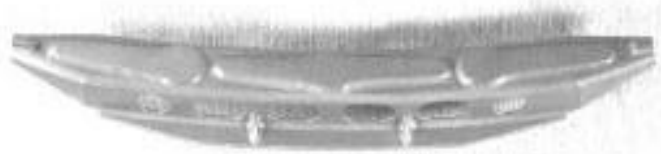

Figare 7; GE90 transition duct beam made from gamma and slated for introduction in 1997.

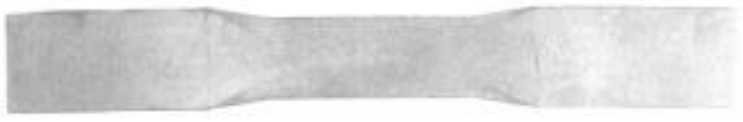

Figure 8. Simulated airfoil test specimen designed to evaluate impact damage at leading edges.
1. B. London and T. J. Kelly, Microstruchure/Property Relationships in Titanium Aluminides and Alloys, ed. Y. W. Kim and R. R. Boyer. TMS, Warrendale, PA, 1992, 285-296.

2. C. M. Austin and T. J. Kelly, Structural Intermetallics, ed, R Darolia et al, TMS, Warrendale, PA, 1993, 143-150.

3. C. M. Austin and T. J. Kelly, Gamma Titanium Aluminides, Ed. Kim, Wagner and Yamaguchi, TMS, Warrendale, PA. 1995. 21-32.

4. Y. W. Kim, Journal of Metals, 46, No. 7, 1994, 30-40.

5. S. C. Huang, U. S. Patent 4,879,092 "Titanium Aluminum Alloys Modified by Chromium and Niobium and Method of Preparation", 1989

6. P. K. Wright, Structural Intermetallics, ed. R. Darolia et al, TMS, Warrendale, PA, 1993, 885.

7. J. M. Larsen et al, Gamma Titanium Aluminides, Ed. Kim, Wagner and Yamaguchi, TMS, Warrendale, PA, 1995, 821-834.

8. D. W. McKee and S. C. Huang, "Oxidation Bchavior of Gamma Titanium Aluminide Alloys under Thermal Cycling Conditions," Corrosion Science, 33 (1992), 1899-1914. 